\title{
Manufacturing of Advanced Composite Wind Turbine Blades for Counter Rotating Vertical Wind Turbine
}

\author{
MIHAELA RALUCA CONDRUZ ${ }^{1 *}$, ION MALAEL ${ }^{1}$, IONUT SEBASTIAN VINTILA ${ }^{1}$, \\ MIHAIL PUSCAS CERNAT ${ }^{2}$
}

${ }^{1}$ Romanian Research and Development Institute for Gas Turbines - COMOTI, 220 D Iuliu Maniu Av., 061126, Bucharest, Romania

${ }^{2}$ Topintechnology Consult, 14 Cuza Voda Str., 106100, Sinaia, Romania

\begin{abstract}
The paper presents the manufacturing process of advanced composite wind turbine blades designed for an experimental counter rotating vertical wind turbine (CR-VAWT). An iterative approach was used to present the manufacturing process of turbine blades starting from presentation of the turbine structure and material description as well as all manufacturing process stages. Two types of turbine blades were successfully manufactured using metallic molds and a cost-effective manufacturing technology. Based on the turbine blades obtained it can be said that the selected manufacturing process showed good results, very similar with results expected in case of using advanced technologies (i.e. autoclave technology).
\end{abstract}

Keywords: composites, wind turbine, renewable energy, manufacturing

\section{Introduction}

Nowadays, the reduction of fossil fuel dependency is an important aspect taken into account by most countries. A reduction of fossil fuel consumption can be made by increasing the renewable energy intake, thereby one of the solutions could be the installation and expansion of wind turbines in domestic areas and development of wind farms [1].

Over the last decades, wind energy has developed rapidly and currently is one of most promising and economically viable energy sources [2]. In European Commission's Energy Roadmap 2050 is stated that investments in renewable technologies will be increased. Until 2050 is foreseen that wind power will provide more electricity than any other renewable technology [3]. Wind turbines can be classified in two main categories, horizontal axis wind turbines (HAWT) and vertical axis wind turbines (VAWT). VAWT type seem to be older than HAWT [4], but in wind energy industry the HAWT type are more popular mainly due to the quantity of energy produced [5]. As the interest for wind energy is rising, VAWTs are being considered a potential alternative to HAWTs for floating offshore wind turbines concept [6] and for households. The interest in VAWTs increased due to the invention of two main turbine types, Darrieus and Savonius vertical turbines [4]. In Figure 1 are presented the Darrieus and Savonius wind turbines along with a particular case of Darrieus turbine - H Darrieus Rotor.

The difference between the two types of vertical wind turbines is the method used to engage the blades in motion in order to produce power. Savonius wind turbine uses aerodynamic drag from the wind to rotate the blades and to produce power, while Darrieus wind turbine uses wind lift forces to rotate the blades. Even if Darrieus turbines have low performances compared with HAWT, they still represent an interest for domestic zones.

*email raluca.condruz@comoti.ro 

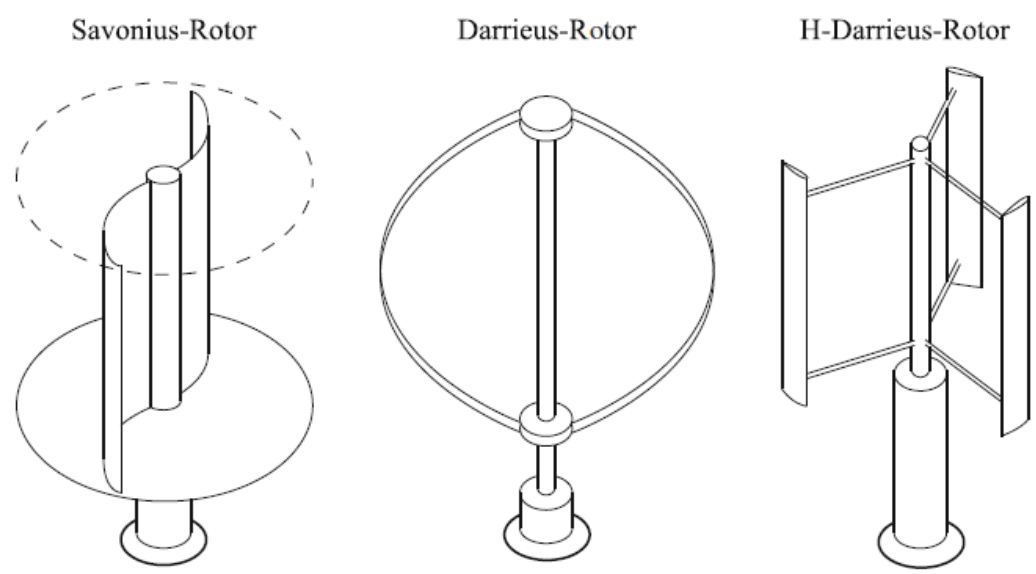

Figure 1. Types of vertical axis wind turbines [4]

In the last decades, studies were conducted to improve Darrieus turbines output power by studying different advanced materials for turbine blades [7-10] and new airfoils designs [11]. Regarding the manufacturing of blades, based on the literature survey it was concluded that fiber reinforced polymeric composites are the most suitable materials for wind turbine blade manufacturing [7-10, 12-16]. The precursors consist in many types of fibers like glass fibers, carbon fibers, aramid fibers or natural fibers and a polymeric matrix (thermoset or thermoplastic matrices). Moreover, in the last decades besides fibers, nanoelements (carbon nanotubes, nanoclay) were added in order to strengthen the material. The most used reinforcement for turbine blades is the E-glass fiber $[12,13,16]$, but carbon fibers or combinations between carbon and glass fibers are recommended to ensure better mechanical strength.

Different methods are employed to manufacture the blades and based on their dimensions, two types of methods can be applied: manual methods and mechanized methods. Usually manual methods are used for small and medium size blades while mechanized methods are used for bigger blades. The main manual method applied is hand lay-up (wet lay-up or prepreg lay-up) and implies manual positioning of materials over molds and afterwards they are cured at room temperature or in an autoclave or an oven. By manual means, two shells are manufactured and joined, along with stiffeners, with adhesive. Among mechanical methods are resin infusion, filament and tape winding which also imply the use of different type of molds $[15,16]$. Resin infusion implies the infusion of resin in a mold where the reinforcement was laid-up, the material is cured afterwards at room temperature, or using heated molds or in an oven. In case of filament winding, the fibers are impregnated as they are arranged over a rotating mold similar to a mandrel and afterwards the material is cured in an oven. All methods present advantages and disadvantages, but considering the cost implied, the lay-up method is considered the most inexpensive if the curing is realized in air or in an oven (the autoclave being an expensive equipment). It was reported that many researchers use computational analyses along with experimental analyses in order to determine and improve turbine performances [17-19]. One solution to ensure a higher energy production is to develop a counter rotating wind turbine (CR-VAWT) [18]. Counter-rotating wind turbines represent a system of two rotors which rotate in opposite directions - one rotor is rotating in clockwise direction and the other in counter-clockwise direction. Also, it was observed that symmetric airfoils provide better performances than nonsymmetrical ones [11]. The interest in composite materials for wind turbine production has increased not only due to their mechanical performances, but also because nowadays there are different methods to recycle them [20,21].

The present paper is focused on the manufacturing process of turbine blades used for an experimental model of a CR-VAWT with symmetrical blades. The experimental model of VAWT is characterized by no stationery permanent magnet generator (PMG) parts. 


\section{Materials and methods}

\section{CR-VAWT design}

Regarding the design of blades, the CR-VAWT presents two types of symmetrical NACA 0021 airfoils. The differences between the airfoils are caused only by the chord length. Further, the airfoil with the chord of $70 \mathrm{~mm}$ will be referred as type 1 blade (larger blade) and airfoil with the chord of 45 $\mathrm{mm}$ will be referred as type 2 blade (smaller blade). Figure 2 shows the 3D CAD model of the experimental wind turbine assembly while Table 1 presents the blade airfoils parameters. The turbine blades were designed with two metallic inserts that are used to attach the mounting brackets that sustain the blades on the shaft.

Table 1. Blade airfoils parameters

\begin{tabular}{|c|c|c|}
\hline Parameter & Type 1 (Larger blade) & Type 2 (Smaller blade) \\
\hline Length of blade [m] & 0.5 & 0.5 \\
\hline Blade chord [m] & 0.07 & 0.045 \\
\hline Airfoil & 0021 & 0021 \\
\hline No. of blades & 3 & 3 \\
\hline Solidity & 0.5 & 0.35 \\
\hline
\end{tabular}

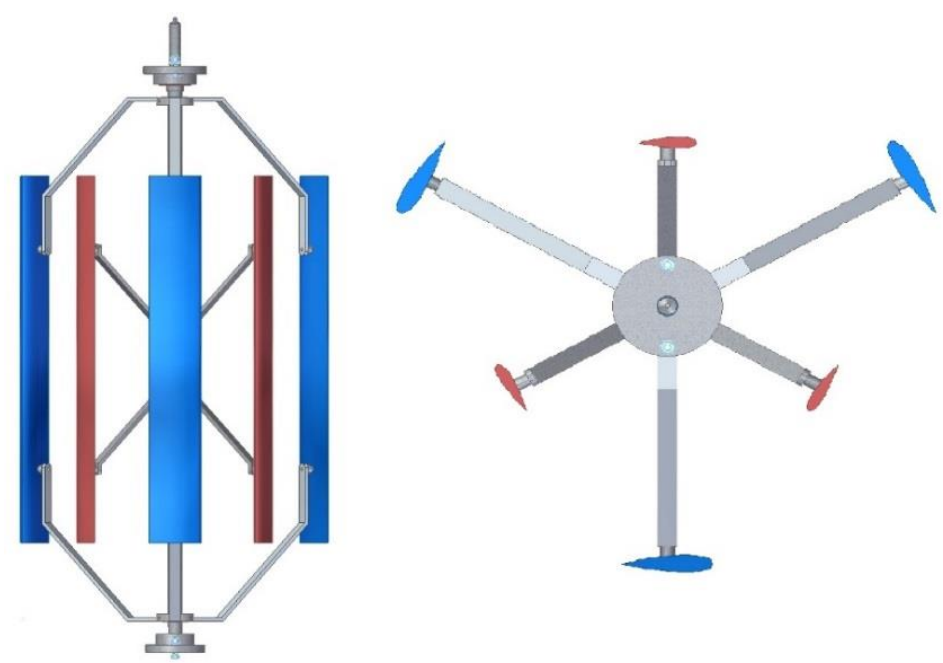

Figure 2. CAD model of the experimental wind turbine assembly

\section{Materials}

The material selected for this application consisted in a carbon fiber reinforced epoxy composite based on a prepreg precursor (HexPly M49/42\%/200T2x2/CHS-3K). The main factors that contributed to the selection of this prepreg were its good mechanical properties in terms of tensile and flexural strength, delamination and impact resistance, also due to the twill carbon fabric which provides the high stiffness necessary to maintain the blade shape. Also, the composite material selected for this application has a low density thus reducing the gravitational forces. Moreover, its light weight could imply that the wind blades could be moved in a reduced intensity wind situation (the wind turbine could be placed even in regions with low wind and still could provide power). In Table 2 can be observed the characteristics and properties of the prepreg used.

Regarding environmental degradation due to rain, moist or salted environments, in previous studies conducted by the authors [22] was observed that short term moisture exposure could have a positive influence on mechanical properties, also moisture desorption could happen in heat presence. To provide a supplementary protection against UV radiation, moisture ingression and particle erosion of the turbine blades, it was selected a compatible protective coating to be applied on the turbine blades surface. 
Table 2. Prepreg characteristics and properties of HexPly M49

from the technical data sheet [23]

\begin{tabular}{|c|c|}
\hline Characteristic/property & Data \\
\hline Fiber & High strength carbon fabric \\
\hline Resin & High toughened epoxy \\
\hline Tow & Tw \\
\hline Weave & 1.47 \\
\hline Nominal laminate density $\left[\mathrm{g} / \mathrm{cm}^{3}\right]$ & 1050 \\
\hline Tensile strength $[\mathrm{MPa}]$ & 68 \\
\hline Tensile modulus $[\mathrm{GPa}]$ & 1000 \\
\hline Flexural strength $[\mathrm{MPa}]$ & 60 \\
\hline Flexural modulus $[\mathrm{GPa}]$ & 730 \\
\hline Compressive strength $[\mathrm{MPa}]$ & \\
\hline
\end{tabular}

\section{Tensile and flexural tests}

Two types of mechanical tests were performed on specimens, tensile and three-point flexural tests. Thereby, 360x250 mm composite laminates were manufactured using 8 plies of HexPly M49/42\%/200T2x2/CHS-3K prepreg with a stacking sequence $\left[0^{\circ} / 90^{\circ}\right]_{4}$. For the three-point flexural tests a composite laminate with a stacking sequence of $\left[-45^{\circ} / 45^{\circ}\right]_{4}$ was also manufactured having similar dimensions. Vacuum bag ensembles were realized and they were cured in a vacuum assisted oven (POL EKO SLN 240). Although curing the materials using a vacuum assisted oven is considered a more economic method than the autoclave, it can provide similar results. The curing cycle was established based on the material datasheet and previous experimental work made with the same material, thus consisting in a heating stage from room temperature until $120^{\circ} \mathrm{C}\left(\sim 2^{\circ} \mathrm{C} / \mathrm{min}\right.$. $)$, temperature holding for $90 \mathrm{~min}$. followed by cooling at room temperature. The laminates were left to cool until room temperature before extraction of the laminate, to avoid the occurrence of internal stresses that can affect its structural integrity.

Tensile test $(250 \times 25 \times 2 \mathrm{~mm})$ and type I flexural test specimens $(100 \times 15 \times 2 \mathrm{~mm})$ were cut using a water jet cutting machine. Each mechanical test was performed on 5 specimens according to standard SR EN ISO:527-4/2000, respective SR EN ISO 14125:2000, using a displacement of $2 \mathrm{~mm} / \mathrm{s}$. The test were performed using Instron 3369 testing machine with a static load cell of $50 \mathrm{kN}$.

\section{Density measurements}

Composite coupons were used to experimentally determine the material's density. It was measured by Archimedes method, using an analytical balance Pioneer PX224 (Ohaus) with a density measurement kit for solids. The fluid used for the measurements was Ethanol (99.3\% purity) with known density variation with temperature. An average value was determined based on 5 measurements.

\section{Turbine blades manufacturing process}

To manufacture the turbine blades, two aluminum molds were designed and manufactured, one for each blade type. Each of the two molds are composed of two individual parts (Figure 3). Because each turbine blade requires two metallic inserts to fasten them onto the vertical axis, two $10 \mathrm{~mm}$ holes were machined on one mold part of each mold assembly, in order to integrate the metallic inserts in one manufacturing stage.

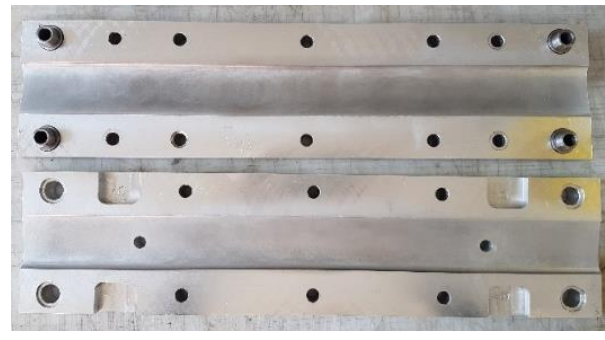

Figure 3. Main components of a metallic mold used for turbine blade manufacturing process 
The manufacturing of the turbine blade consisted in an iterative process which included the lay-up of the materials on the active mold surfaces (interior surfaces). The lay-up process was realized at room temperature, followed by a vacuum bag assembly prior for curing process. Due to the reduced dimension of the structures, the same curing cycle and vacuum assisted oven (POL EKO SLN 240) was used as for composite laminates manufacturing.

Moreover, the same manufacturing process stages and curing cycle were used for all the turbine blades. Before laying-up the prepreg plies, the active mold surfaces (which make contact with the prepreg) had to be prepared. Initially, the molds active surfaces were degreased with acetone and then treated with a release agent to facilitate the removal of cured structure without damaging the mold or the composite structure. Hereinafter, the manufacturing process of one type 2 wind turbine blade is presented in details. The difference between the type 1 and type 2 blades manufacturing consist in the prepreg plies dimensions (due to the fact that the type 1 blade has a higher cord that the type 2 blade, $0.07 \mathrm{~m}$ vs. 0.045).

From a prepreg roll, two plies were cut at optimum size of 520x 100mm (dimensions experimentally obtained from previous attempts to manufacture the turbine blades). The turbine blades must be provided with end caps, therefore, an additional $20 \mathrm{~mm}$ of material was added to the $500 \mathrm{~mm}$ base length, so that, at each end of the blade, the material will be folded $10 \mathrm{~mm}$ onto the mold, to create an attachment base for the caps. Regarding the width of the blade, $94 \mathrm{~mm}$ of material were necessary for the blade circumference, but additional $6 \mathrm{~mm}$ were added to ensure an overlapping of the material plies. Two metallic inserts were realized to attach the mounting brackets that sustain the blades on the shaft. They were designed to be integrated between prepreg plies to ensure a higher resistance of the grip area compared with the case of a glued interface between metallic insert and blade surface. Thereby, to integrate the inserts two $10 \mathrm{~mm}$ diameter perforations were made in one prepreg ply. All prepreg plies dimensions are presented in Figure 4, while the metallic inserts are presented in Figure 5 a.

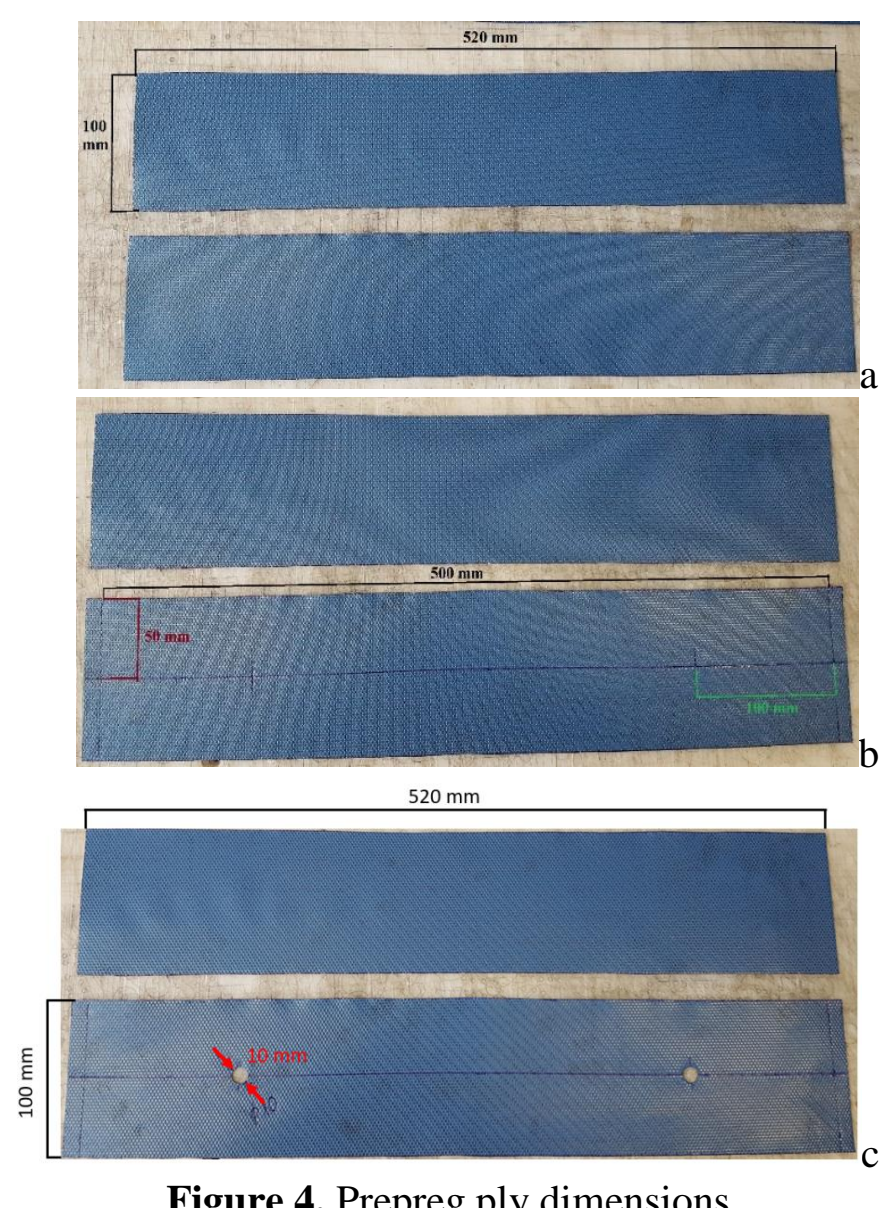



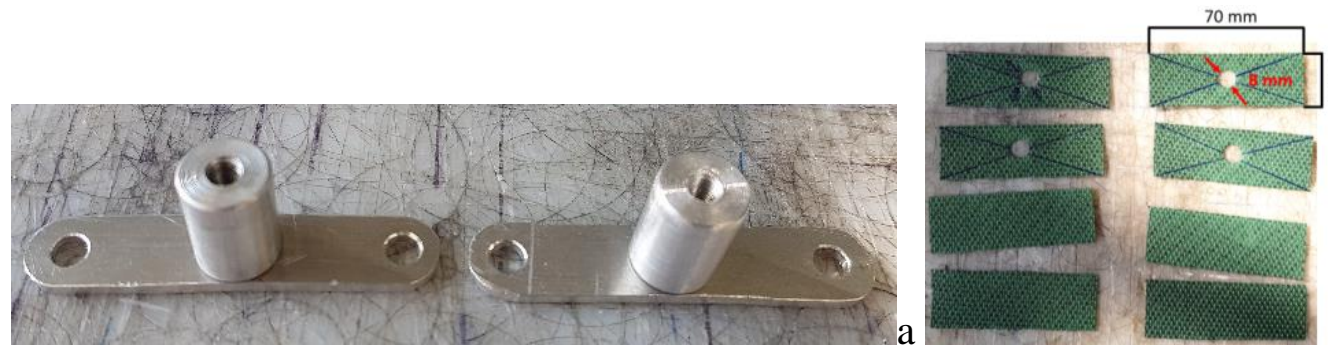

$\mathrm{b}$

Figure 5. a) Metallic inserts; b) Reinforcement prepreg plies

Regarding the position of metallic inserts related to the blade profile, it must be stated that they are placed at half of the chord length and $100 \mathrm{~mm}$ from the blade's edge. The metallic insert surface was grinded with sand paper (granulation 600) to obtain a rough surface and to ensure a better adhesion between polymeric composite and metallic material.

To ensure additional resistance in the inserts area (to secure and stiffen the area where the inserts were added), 4 prepreg plies (Figure 5b), with dimensions of 70x $25 \mathrm{~mm}$ were added, on the interior of the blade, as follows: 2 plies with $8 \mathrm{~mm}$ diameter perforations were placed before the insert and 2 plies without perforations were after the metallic insert, as it is shown in Figure 6 where the laying-up sequence is presented.

Firstly, one of the prepreg protection foils was detached and two reinforcement prepreg plies were laid-up over the metallic insert. Afterwards, the perforated prepreg ply was placed over the ensemble composed of metallic insert and reinforcement plies. The other two reinforcement plies were placed on top of the metallic inserts followed by the last prepreg ply (520x100 mm without holes).

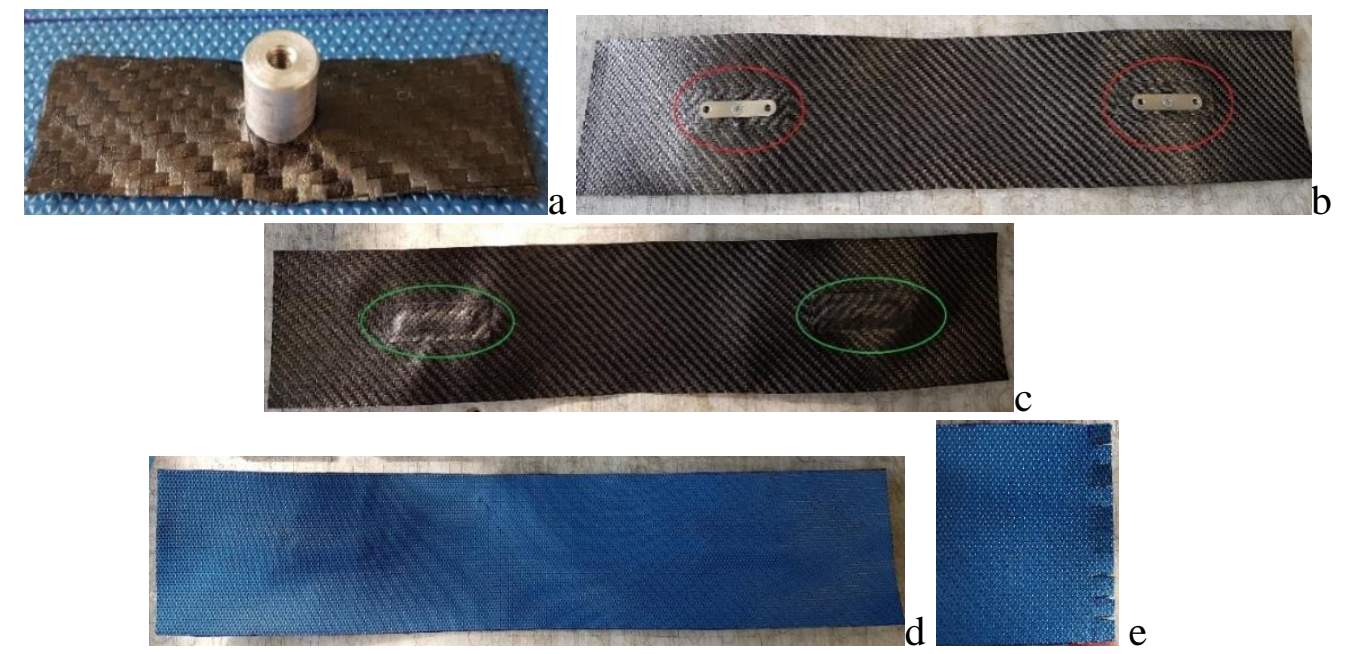

Figure 6. Layering sequence including the integration of metallic inserts

The lateral sides of the material were cut to facilitate the settlement on the lateral mold (Figure 6e) and the ensemble composed of all prepreg plies and metallic inserts was placed on the mold component with ports for the inserts (Figure 7).

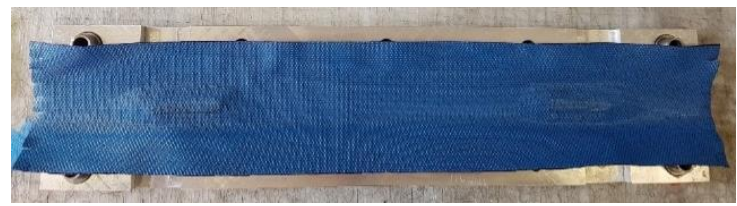

Figure 7. Ensemble settlement on the mold 
An interior vacuum bag was realized and afterwards it was laid down along with release film to ensure an easy removal of the vacuum bag. The interior vacuum bag was covered with the lateral sides of the prepreg plies forming a cylinder. The second mold component was placed and secured with M8 screws. A breather was placed over the metallic mold, covering all the sharp edges and the screws to avoid the vacuum bag break. An external vacuum bag was connected to the interior vacuum bag with heat resistant sealing tape resulting in one complex vacuum bag which ensured the compression of the material on the mold walls. In Figure 8 can be observed the integration of the interior vacuum bag and the final ensemble. The vacuum ensemble was introduced in the oven for curing. The same curing cycle was used as in case of composite laminates manufactured for the testing campaign. After the curing process, the composite structure was removed from the mold and can be observed in Figure 9.

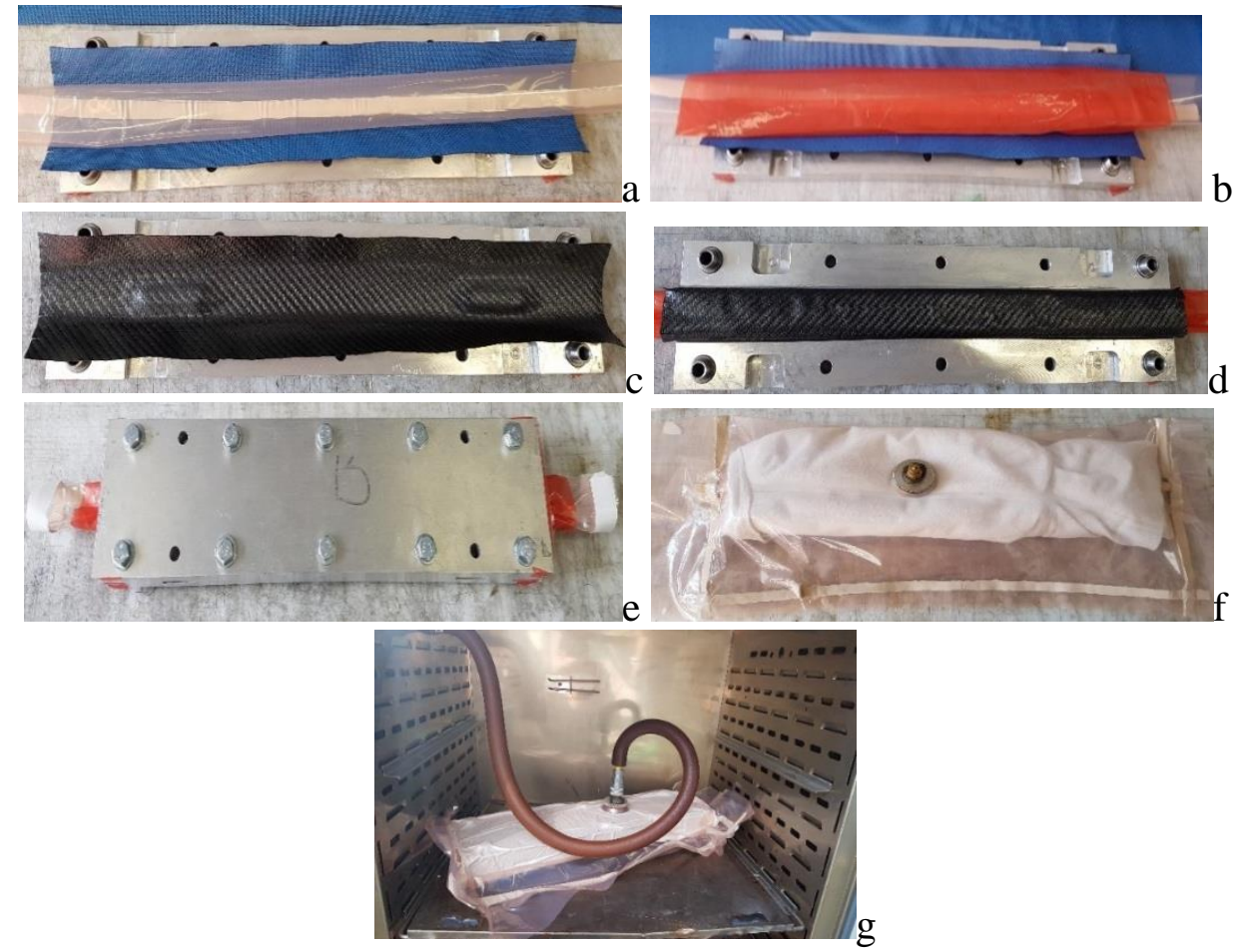

Figure 8. Manufacturing of vacuum bag ensemble

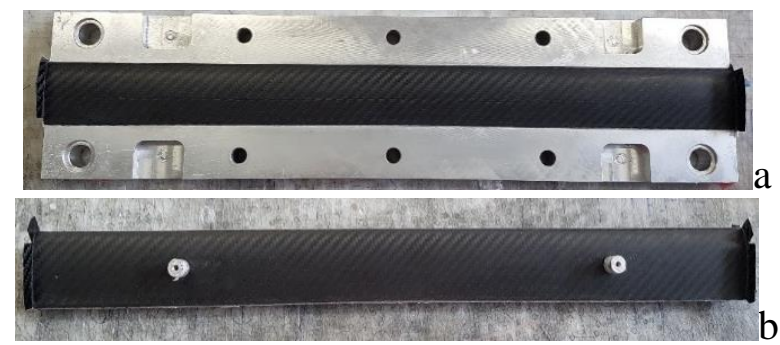

Figure 9. Composite structure after mold release

Using the same material and the same curing cycle, composite end caps were manufactured (Figure 10a). The caps were glued with a compatible adhesive (bicomponent epoxydic adhesive Araldite AW 106 with Hardener HV 953 U). In Figure 10b can be observed the attachment of end caps. 


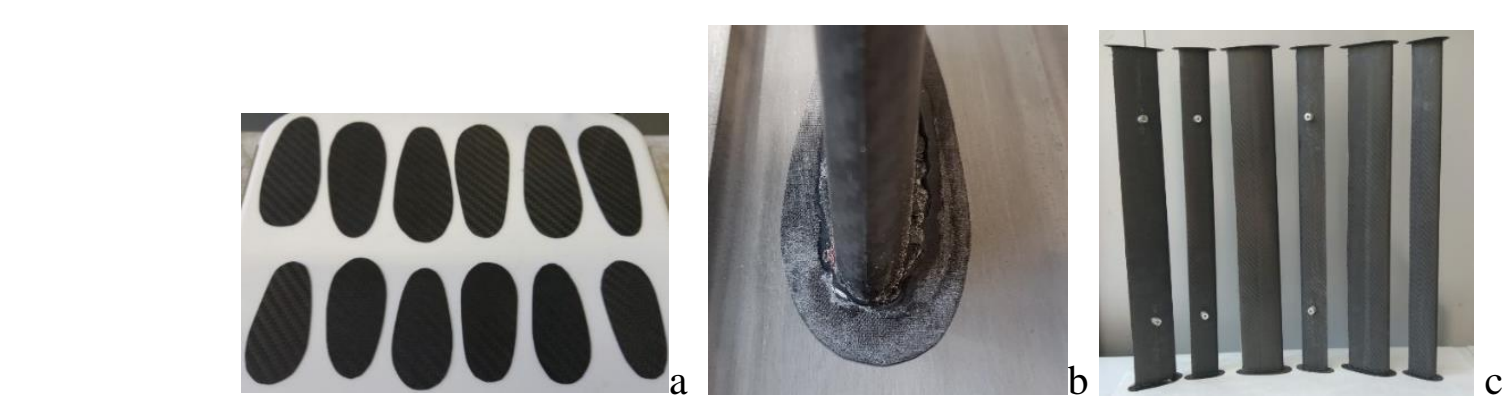

Figure 10. a) Turbine blade end caps; b) Attachment of the end caps;

c) Composite wind turbine blades with end caps

After attaching the caps, the wind turbine blades were coated first with a primer with the goal of a bond coat between the composite surface and the paint, and afterwards an acrylic blue paint was sprayed on the surface (Figure 11).

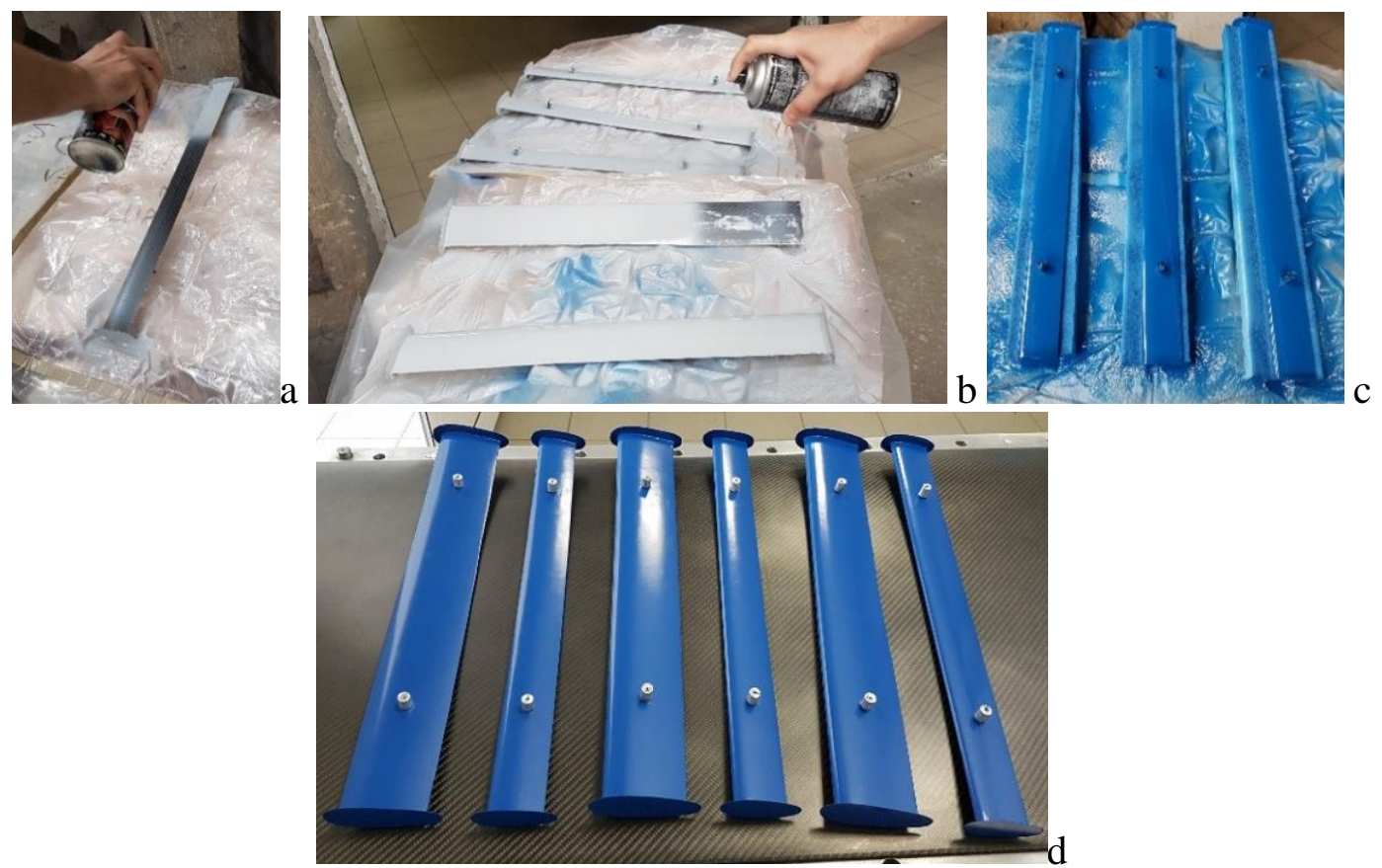

Figure 11. Coating process of the wind turbine blades

The same manufacturing steps were applied in order to manufacture type 1 blades (larger blades), the only difference being the prepreg ply's width.

\section{Wind turbine testing}

The wind turbine blades were assembled on the shaft and they were tested in a wind tunnel at different air speeds in order to determine the revolution speed of both types of blades. A manometer PeakTech 5145 was used to measure the air velocity from the wind tunnel and a tachometer PeakTech 2795 was used to measure the blade revolution speed. Figure 12 presents the CR-VAWT during testing. 


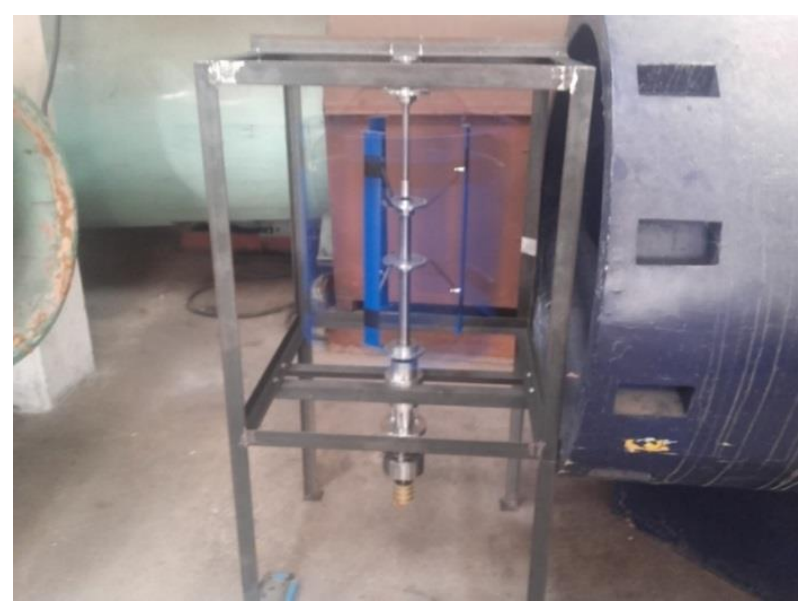

Figure 12. The wind turbine during testing

\section{Results and discussions}

A solution to improve the performances of wind turbines is to develop counter rotating wind turbines with the airfoils made of fiber reinforced composites. Even if the horizontal wind turbines are most often used, the vertical wind turbine start to draw ahead of horizontal turbines, especially for domestic applications.

During this study, two types of mechanical tests were performed in order to determine the tensile and flexural properties of the selected composite material used for CR-VAWT blades. The mechanical test performed showed that the composite shows a good tensile strength (average value of $926 \mathrm{MPa}$ ) and a good flexural strength (average value of $234 \mathrm{MPa}$ in case of the $-/+45^{\circ}$ stacking sequence, respective $520 \mathrm{MPa}$ in case of the $0^{\circ} / 90^{\circ}$ stacking sequence) as it can be seen in Figure 13 where the test curves are showed. The carbon fiber composite has superior mechanical properties compared with glass fiber composite, as the configurations tested by Bej et.al. [15]. Moreover, the experimentally determined density was $1420 \mathrm{~kg} / \mathrm{m}^{3}$ and it shows that the blades are light enough to be easily set in motion by the wind.

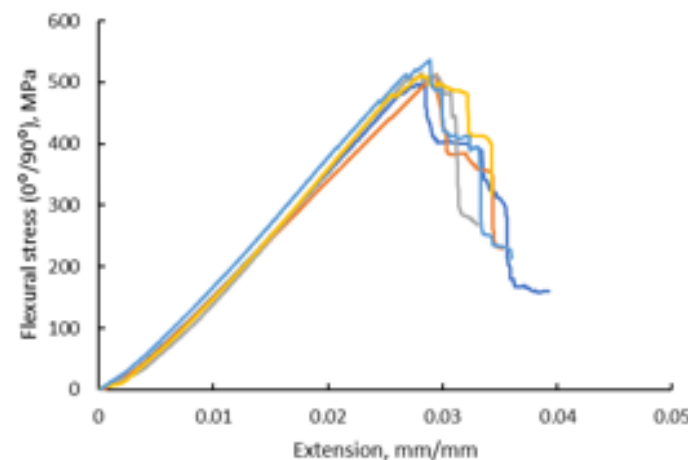

$\mathrm{a}$

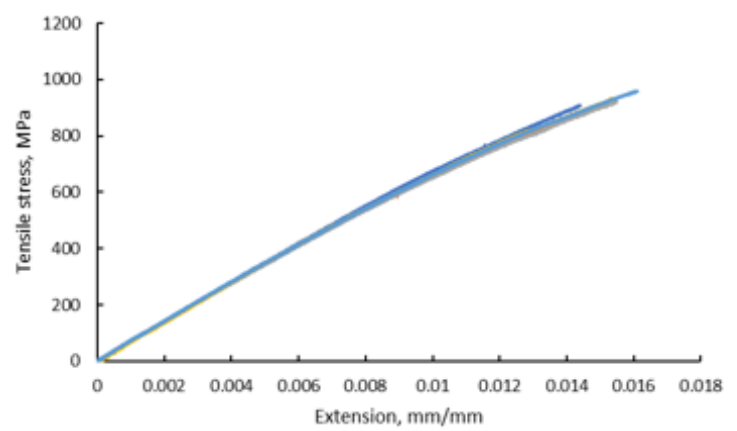

b

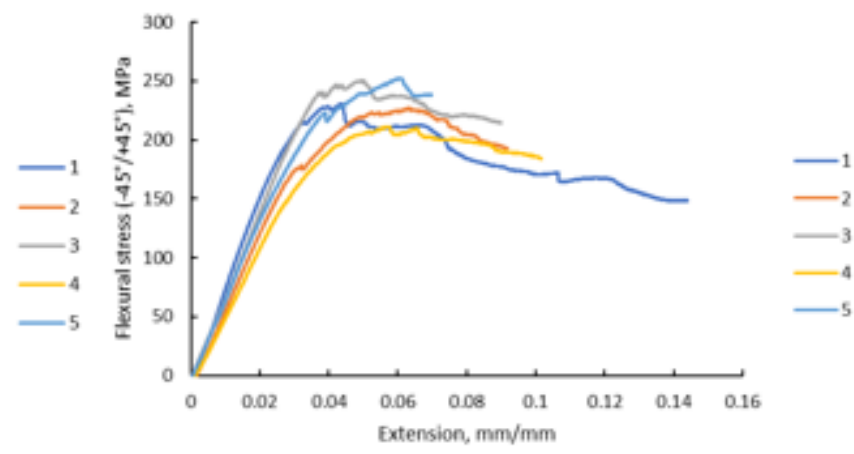

b

Figure 13. Mechanical test results in case of flexural test with Composite laminate with a stacking sequence of $\left[0^{\circ} / 90^{\circ}\right]_{4}(\mathrm{a})$, respective $\left[-45^{\circ} / 45^{\circ}\right]_{4}$ (b) and in case of tensile test (c) 
As it was presented, two types of turbine blades for a CR-VAWT were successfully manufactured using metallic molds and a cost-effective manufacturing technology. Using a vacuum assisted oven and prepreg precursor were obtained the same results as in case of using the autoclave technology [24]. The metallic molds used were designed to ensure metallic inserts attachment during the composite material lay-up in order to increase the mechanical resistance of the blade in the grip area.

By using enclosed metallic molds, it was allowed the blade manufacturing as a single shell (not as two shells bonded with adhesive). The shell consisted in a continuous prepreg layer that ensured a higher structural stability compared to conventional turbine blades manufacturing processes.

The CR-VAWT assemble was tested in the wind tunnel and the results presented in Figure 14 were obtained. It was observed that different revolution speeds were obtained for the two types of blades, the type 1 blades moved at a higher speed compared with the type 2 blades. After testing, no defects were observed on the turbine blades.

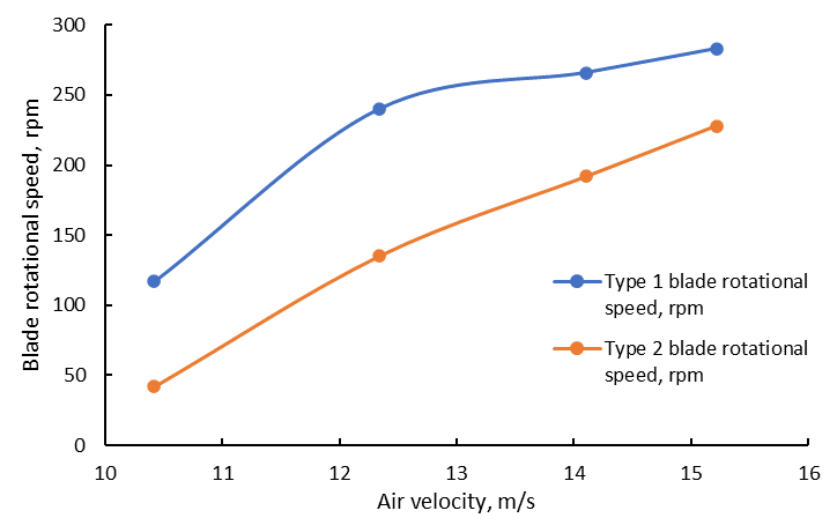

Figure 14. The evolution of blade rotational speed as a function of air velocity

Based on literature survey it can be said that multiple studies were made on counter rotating wind turbines but they present only designs and numerical studies [25-28], very few present actual experimental studies or manufacturing processes of turbine blades or other components. Studies regarding the performance evaluation of different CR-VAWT were realized using wood turbine blades $[29,30]$.

\section{Conclusions}

In the present study, an experimental model of a counter-rotating vertical axis wind turbine blades were manufactured.

The manufacturing process was explained in detail, starting from the presentation of airfoils CAD design, of the advanced material used for manufacturing, selection of the curing cycle and curing method.

Tensile and 3-point bending mechanical tests were performed and it was concluded that the material can ensure enough mechanical strength for the turbine blades. The material was selected based on the requirements imposed of the vertical axis turbine blades in terms of mechanical properties, high stiffness, low density, environmental compatibility.

Two types of CR-VAWT blades were manufactured, they consisted in six NACA0021 airfoils divided in two categories: three type 1 blades (larger blades) and three type 2 blades (smaller blades). The difference between the blades is caused by the chord length.

The manufacturing process selected represent a cost-effective method, vacuum assisted curing in the oven, method that provides comparable results as by the autoclave technology. The manufacturing process has been successfully accomplished, six wind turbine blades were manufactured and the CRVAWT was assembled and tested in a wind tunnel to determine its performance. It was observed that 
different revolution speeds were obtained for the two types of blades, the type 1 blades moved at a higher speed compared with the type 2 blades. The possibility to integrate this type of wind turbine in domestic areas is under discussion.

Acknowledgement. This work was carried out within POC - Competitiveness Operational Program, supported by the EU and Romanian Minister of Research and Innovation funds, project number POC 9/01.09.2016, MySmis 105890, ID P_40_309.

\section{References}

1. TIMMONS D., HARRIS J.M., ROACH B., The Economics of Renewable Energy, Global Development and Environmental Institute, Tufts University, 2014

2. COMSAN M.N.H., Wind Energy for Sustainable Development, Proceedings of the $3^{\text {rd }}$ Environmental Physics Conference, Egypt, 2008

3***European Union, Energy Roadmap 2050, Publications Office of the European Union, 2012

4.SCHAFFARCZYK A.P, Introduction to Wind Turbine Aerodynamics, Green Energy and Technology, Springer-Verlag Berlin Heidelberg, 2014

5. HUI I., CAIN B.E., DABIRI J.O., Public receptiveness of vertical axis wind turbines, Energy Policy 112 (2018), 258-271

6. BAYATI I., FOLETTI S., TARSITANO D., BELLOLI M., A reference open data vertical axis wind turbine, with individual pitch control, for code validation purposes, Renewable Energy 115 (2018) 711720

7. BRONDSTED P., LILHOLT H., LYSTRUP A., Composite Materials for Wind Power Turbine Blades, Annu. Rev. Mater. Res., 505-538, 2005

8. BORTOLOTTI P., Carbon Glass Hybrid Materials for Wind Turbine Rotor Blades, Master Thesis, Delft University of Technology, 2012

9. EKER A.A., EKER B., General Assessment of Fiber - Reinforced Composites Section in Wind Turbine Blades, Recent Advances in Composite Materials for Wind Turbines Blades, BrahimAttas (Ed.), ISBN 978-0-9889190-0-6, 2013

10. CHEHOURI A., Advances in composite wind turbine blades: A comparative study, Anchor Academic Publishing, ISBN 3954892308, 2014

11. HASHEM I., MOHAMED M.H., Aerodynamic performance enhancements of H-rotor Darrieus wind turbine, Energy 142, pp. 531-545, 2018

12. MISHNAEVSKY L. Jr., BRANNER K., PETERSERN H.N., BEAUSON J., MCGUGAN M., SØRENSEN B.F., Materials for Wind Turbine Blades: An Overview, Materials, 10, 1285, 2017

13. GOLFMAN Y., Materials for Turbine Power Blades, Reinforcements, and Resins, in Hybrid Anisotropic Materials for Wind Power Turbine Blades, 55- 88, 2012

14. GOLFMAN Y., Manufacturing Technologies for Turbine Power Blades, in Hybrid Anisotropic Materials for Wind Power Turbine Blades, 89 - 118, 2012

15. BEJ A., BORIDEASU I., MILOS T., BADARAU R., Consideration Concerning the Mechanical Strength of Wind Turbine Blades Made of Fiberglass Reinforced Polyester, Mater. Plast., 49(3), 2012, 212-218

16.*** National Research Council. Assessment of Research Needs for Wind Turbine Rotor Materials Technology. Washington, DC: The National Academies Press. 1991

17. ALAIMO A., ESPOSITO S., MESSINEO A., ORLANDO C., TUMINO D., 3D CFD Analysis of a Vertical Axis Wind Turbine, Energies, 8, pp. 3013 - 3033, 2015

18. LEE S., SON E., LEE S., Velocity interference in the rear rotor of a counter-rotating wind turbine, Renewable Energy 54, pp. 235-240, 2013

19. JIANG Y., HE C., ZHAO P., SUN T., Investigation of Blade Tip Shape for Improving VAWT Performance, J. Marine Sci. Eng., 8, 225, 2020 
20. BEAUSON J., MADSEN B., TONCELLI C., BRONDSTED P., BECH J.I., Recycling of shredded composites from wind turbine blades in new thermoset polymer composites, Composites: Part A 90, pp. 390-399, 2016

21. GOODSHIP V., Management, recycling and reuse of waste composites, Woodhead Publishing Limited, 2010

22. CONDRUZ M., PARASCHIV A., PUSCASU C., VINTILA I.S., Tensile behavior of humid aged composites for helicopter external fuel tank development, Matec Web of Conferences 145, 02004, 2018 23.*** HexPly M49 Data Sheet, 2015

24. VINTILA I.S., CONDRUZ M.R., FUIOREA I., MALAEL I., SIMA M., Composite Wind Turbine Blade using Prepreg Technology, $6^{\text {th }}$ CEAS Air \& Space Conference Proceeding, pp. 5-14, ISBN: 978973-0-25597-3, 2017

25. OPRINA G., CHIHAIA R.A., EL-LEATHEY L.A., NICOLAIE S., BABUTANU C.A., VOINA A., A Review on Counter-rotating Wind Turbines Development, Journal of Sustainable Energy, Vol.7, No.3, 2016

26. DIDANE D.H., ROSLY N., ZULKAFLI, M.F., SHAMSUDIN S.S., Numerical investigation of a novel contra-rotating vertical axis wind turbine, Sustainable Energy Technologies and Assessments, Vol.31, pp. 43-53, 2019

27. SAI. P.C., YADAV R.S., RAJ N., GUPTA G.R.K., Design and simulation of high efficiency counter-rotating Vertical Axis Wind Turbine arrays, 2014 International Conference and Utility Exhibition on Green Energy for Sustainable Development (ICUE), IEEE, 2014

28. DABIRI, J.O., Potential order-of magnitude enhancement of wind farm power density via counterrotating vertical-axis wind turbine arrays, Journal of Renewable and Sustainable Energy 3, 043104, 2011 29. DIDANE D.H., MAKSUD S.M., ZULKAFLI, M.F., ROSLY N., SHAMSUDIN S.S., KHALID A., Experimental Study on the Performance of a Savonius-Darrieus Counter-Rotating Vertical Axis Wind Turbine, IOP Conf. Series: Earth and Environmental Science, 268, 012060, 2019

30. CHAICHANA T., CHAITEP S., Performance Evaluation of Co-Axis Counter-Rotation Wind Turbine, Energia Procedia, 79, pp. 149-156, 2015

Manuscript received: 27.03 .2020 